\title{
Pattern of child and adolescent psychiatric disorders among patients consulting publicly-funded child psychiatric clinics in Saudi Arabia
}

\author{
A.A. Al-Habeeb, ${ }^{1}$ N.A. Qureshi' and T.A. Al-Maliki ${ }^{1}$
}

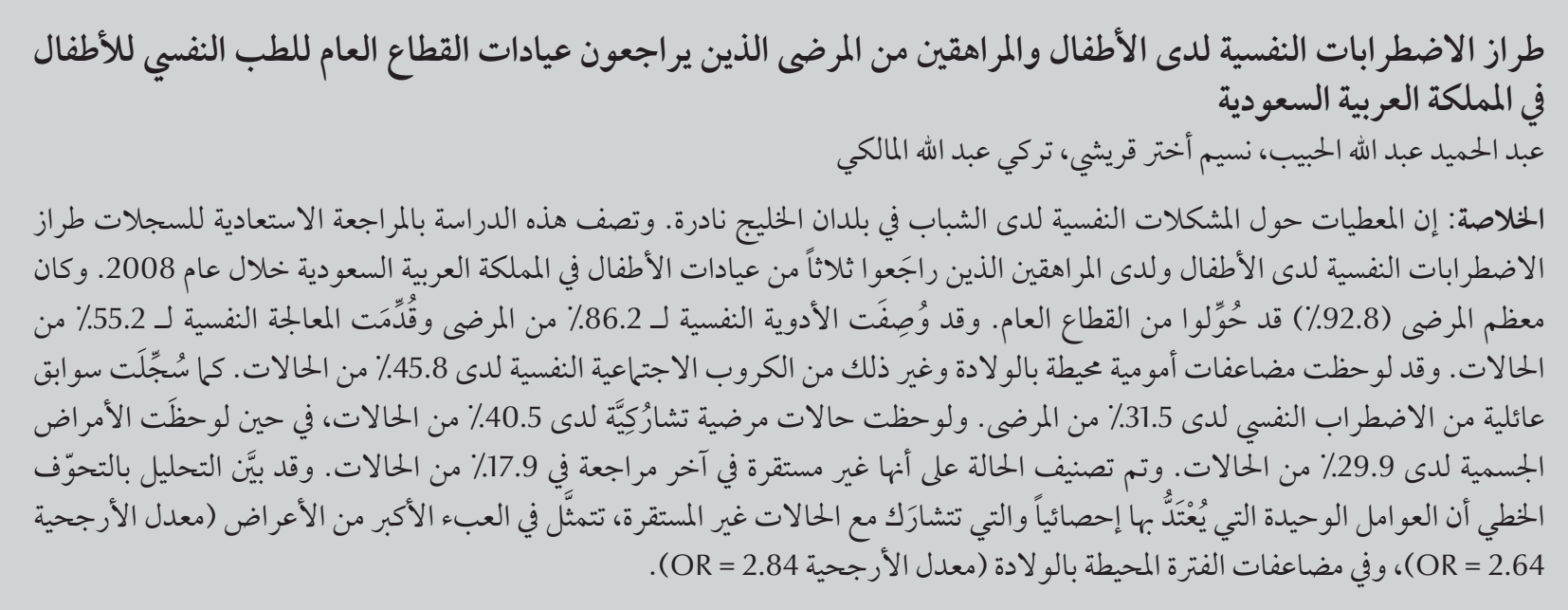

ABSTRACT Data about psychiatric problems among young people are scarce in the Gulf countries. This retrospective review of records describes the pattern of child and adolescent psychiatric disorders among patients consulting 3 child psychiatric clinics in Saudi Arabia during the year 2008. Most patients were referred from the public health sector (92.8\%). Psychotropic drugs were prescribed for $86.2 \%$ of patients and psychotherapy for $55.2 \%$. Maternal perinatal complications and other psychosocial stressors were noted in almost $45.8 \%$ of cases. Family history of psychiatric disorder was reported in $31.5 \%$ of patients. Psychiatric comorbidity was noted in $40.5 \%$ of cases while physical diseases were noted in $29.9 \%$. The outcome was classified as unstable at the last consultation in $17.9 \%$ of cases. In a linear regression analysis the only factors significantly associated with unstable outcome were a higher load of symptoms (OR 2.64) and perinatal complications (OR 2.84).

Profil des troubles psychiatriques chez des enfants et adolescents consultant en établissements de soins psychiatriques pour enfants à financement public en Arabie saoudite

RÉSUMÉ Les données sur les problèmes psychiatriques des jeunes sont rares dans les pays du Golfe. Le présent examen rétrospectif des dossiers médicaux décrit le profil des troubles psychiatriques des enfants et des adolescents qui consultaient dans trois établissements de soins psychiatriques pour enfants en Arabie saoudite pendant l'année 2008. La plupart des patients venaient du secteur public de la santé (92,8\%). Des médicaments psychotropes ont été prescrits à $86,2 \%$ et une psychothérapie à 55,2 \% des patients. Des complications maternelles périnatales et d'autres facteurs de stress psychosociaux ont été observés dans presque 45,8\% des cas. Sur l'ensemble des patients étudiés, 31,5\% avaient des antécédents familiaux de troubles psychiatriques. Une comorbidité psychiatrique a pu être observée dans 40,5\% des cas et physique dans 29,9\%. À l'issue de la dernière consultation, $17,9 \%$ des cas ont été classés comme instables. Dans une analyse de régression linéaire, les seuls facteurs significativement associés à une évolution instable étaient le nombre élevé de symptômes (O.R. 2,64) et les complications périnatales (O.R. 2,84). 


\section{Introduction}

Approximately one-fifth of children and adolescents are afflicted annually by mental health problems, and their psychiatric morbidity accounts for 5 of the 10 leading causes of disability for those aged 5 years and above $[1-3]$. Despite this, mental health care for children and adolescents including development of adequate clinical services and programmes for staff training and research has received little attention from health planners in Saudi Arabia and other Arab nations as compared to more developed countries [4]. Notably there is a huge research database in the industrialized countries that assists in the development of good quality health care services for children and adolescents [5-10]. Most of the studies reported externalizing disorders such as attention deficit hyperactivity disorder (ADHD) as the most common, followed by internal disorders such as depression and anxiety plus co-occurrence of internal and external disorders [11-16]. Overall childhood psychopathology is the harbinger of similar (homotypic) or dissimilar (heterotypic) adult psychopathology.

In the Gulf countries the literature on psychiatric problems in the child and adolescent population is sparse [17-19]. There is no database on child and adolescent psychopathology from primary and secondary care in Saudi Arabia. Moreover, despite the establishment of child psychiatric clinics, no evaluation research has been carried out. This study in Saudi Arabia was an audit of the recorded sociodemographic and clinical information of children and adolescents attending publicly-funded child psychiatric clinics. The focus was on psychopathology, utilization patterns of services and treatment outcomes. It was hoped that the study findings would assist in further planning and development of the health care offered to children and adolescents with mental health disorders.

\section{Methods}

\section{Study design}

The study was a retrospective audit of the medical records of patients who attended child psychiatric clinics during the 1 -year period 1 January to 31 December 2008. The records of both old and new patients were reviewed, i.e. patients who had consulted during earlier years but continued to visit into the year 2008 were also included.

\section{Setting}

Out of the 6 well-established Ministry of Health child and adolescent psychiatric clinics in Riyadh we selected 3 clinics randomly (by lottery) for data collection from 3 different cities: Al-Amal Complex for Mental Health in Riyadh, Maternity and Children Hospital in Buraidah and Al-Amal Complex for Mental Health in Dammam. These clinics accept patients aged $\leq 18$ years and are staffed by well qualified, experienced psychiatrists.

\section{Sample}

All records of patients $(n=899)$ who consulted these clinics during the year 2008 were reviewed; 335 from Riyadh, 235 from Dammam and 329 from Buraidah. For this purpose a computer list of all child and adolescent patients who attended during the year 2008 was requested from the medical records section of the 3 treatment centres.

\section{Data collection}

The records were reviewed extensively to abstract data onto a pre-designed semi-structured sheet: background information (10 variables) and clinical information (26 variables). The data included were: sociodemographic variables, risk factors, mental health problems, comorbid physical conditions, utilization pattern of prescribed therapies, sources of referral and consultations, and treatment outcomes. Two investigators prepared the data collection sheet, then an independent investigator reviewed the items. Any disagreements were resolved and all 3 researchers agreed on the final list of items to be included.

Three psychiatrists from the selected clinics were briefed in a mini-workshop about how to abstract the relevant data from the files and note it on a predesigned data collection sheet (available from the authors on request). During debriefing the field workers received clarification about any item on the sheet that they could not understand. Furthermore the chief investigators were available by telephone for consultation throughout the data collection phase.

Patients' medical files contained multiple sources for data extraction, including consultant psychiatrists' initial and follow-up evaluation notes, social workers' follow-up reports, psychologists' evaluation and IQ assessment sheets, in- and outpatient nursing observations, records of emergency visits, appended incoming referral notes, laboratory forms, vital sign documentation forms and internal and outgoing referrals. The clinics use Diagnostic and Statistical Manual of Mental Disorders, 4th edition (DSM-IV) criteria for diagnosis, together with DSM guidelines for prescribing psychotropic drugs and psychosocial treatment modalities.

\section{Data analysis}

Data was entered into the computer and cleaned. Analysis was done using descriptive statistics. Risk ratios were estimated by comparing sociodemographic and clinical variables with overall outcome noted at the patient's last visit and for this purpose all the selected variables were categorized into binary data. A $P$-value of 0.05 or less was considered significant.

\section{Results}

\section{Sociodemographic variables}

There psychiatric records of $899 \mathrm{pa}-$ tients who attended during the year 
2008 were analysed. The mean age of the study patients was 9.2 (SD 3.7) years (range $1-20$ years). These included 5 patients aged over 18 years who had continued their follow-up in the clinics even though they were eligible for referral to adult clinics for further diagnosis and treatment. Male patients outnumbered their female counterparts (55.5\% versus $44.5 \%)$ and a majority of patients were Saudi nationals (92.2\%) (Table 1).

About two-thirds of the children and adolescents were enrolled in different grades in special schools (63.6\%). Most of the children were from cities (96.8\%) with only $3.2 \%$ coming from rural areas.

Parental consanguinity, defined as marriage between close blood relatives, was noted for $49.8 \%$ of patients. The mean number of siblings of studied patients was 6.1 (SD 3.7) (range 1-18). The order of the patients among first-degree siblings was as follows: first child $(17.8 \%)$, second (16.1\%), third (16.0\%), fourth (11.9\%), fifth (8.0\%), sixth (6.8\%) and last (6.0\%).

\section{Consultation patterns and clinical variables}

The key informant was most commonly the mother $(81.2 \%)$; only rarely was the father $(9.7 \%)$ oranotherpersoninvolved (6.2\%) (data missing for 2.9\%). Most of the children and adolescents (92.8\%) had been referred by a public health facility, while only a minority came from the private sector (1.1\%) (data missing for $6.2 \%)$. Patients were referred mainly for diagnosis and management $(77.9 \%$ of cases) or a medical report (5.0\%); in $17.0 \%$ of cases no reason was noted. The mean of number of visits made by the patients over the study period was 13.9 (range 1-35).

A history of antenatal, natal and postnatal complications concerning the mothers was noted for $45.8 \%$ of studied patients. These were most often linked to neonatal admissions to neonatal intensive care units of specialist hospitals, ranging from a few days to several days. This information was missing in $8.7 \%$ of patients' records.

\section{Psychological and neurological symptoms}

The children presented with a variety of psychological and neurological symptoms (Table 2). The onset of symptoms was mostly during early childhood ( $\leq 5$ years) $(94.8 \%)$ rather than later ( $0.3 \%)$ (data missing in $8.7 \%$ of cases). The most common symptoms were hyperactivity $(42.9 \%)$ poor scholastic performance $(32.9 \%)$ delayed milestones $(28.4 \%)$, anxiety and related manifestations (17.5\%) attention and concentration difficulties (13.5\%) and impulsivity (13.3\%).

One or more previous psychiatric consultations at the study clinics before the period of this study were noted for almost half of patients (48.6\%). Possible stressors, preceding or continuing, noted in half of patients records (50.8\%) were related to a variety of factors including large and dysfunctional families, multiple marriages, financial problems, residential problems, parental problems and educational problems.

\section{Diagnoses}

The most common diagnosis made either at the index interview or decided later some time during follow-up or at discharge was mental retardation in $30.2 \%$ (borderline, mild, moderate, severe to profound). Less common were: anxiety disorders (16.1\%); attentiondeficit hyperactivity disorder (ADHD) (13.2\%); autistic spectrum disorders (12.5\%); and seizure disorders (9.7\%). Rarer still were: mood disorders (4.2\%); school refusal (4.2\%); enuresis and encopresis (3.1\%); psychosis (2.9\%); and other disorders (Table 3).

\section{Comorbid psychiatric disorders}

The mental disorders mentioned above were co-occurring with another psychiatric disorder in $40.5 \%$ of cases. Most commonly this was cases of mental retardation coexisting with epilepsy, ADHD, autistic spectrum disorder, speech disorder or an incontinence problem. Some cases of anxiety were coupled with depression, school refusal or other problems (e.g. tics, stuttering). Three or more concurrent psychiatric disorders were reported in $11.6 \%$ of cases. The most common combination was mental retardation coexisting with epilepsy and $\mathrm{ADHD}$, with autistic disorder and epilepsy, or with enuresis and encopresis.

\section{Comorbid physical disorders}

A concurrent diagnosis of a physical disorder was noted in the records for $29.9 \%$ of patients $(20.1 \%$ had 1 disorder and $9.8 \%$ had 2 physical disorders). These were most commonly neurological syndromes or congenital malformations. As a corollary, the patients were noted to develop mental disability ( $18.7 \%$ of patients), physical disability (2.8\%) and both (1.6\%) (information missing in $77.0 \%$ of case records). Information about supportive diagnostic laboratory investigations and psychological testing carried out (mainly IQ and personality assessment) were available in 58.2\% and $47.2 \%$ of case records respectively.

\section{Family history}

In $31.3 \%$ of medical records there was a family history of similar or different psychiatric disorders in family members (parents and siblings and seconddegree relatives).

\section{Drug and psychotherapy prescribing pattern}

The psychotropic drug and psychotherapy prescribing pattern noted in the records of patients at the index interview and at the current/last evaluation is shown in Table 4. One or more psychotropic drugs were prescribed at the index interview for $86.2 \%$ of patients, mostly antipsychotics, anticholinergics, antidepressants plus selective serotonin reuptake inhibitors, psychostimulant 


\begin{tabular}{|c|c|c|c|c|c|}
\hline \multirow[t]{3}{*}{ Risk factor } & \multirow[t]{3}{*}{ No. } & \multirow[t]{3}{*}{$\%$} & \multicolumn{2}{|c|}{ Outcome } & \multirow[t]{3}{*}{ OR $(95 \% \mathrm{Cl})$} \\
\hline & & & Stable & Unstable & \\
\hline & & & No. & No. & \\
\hline \multicolumn{6}{|l|}{ Age (years) } \\
\hline$\leq 10$ & 570 & 63.4 & 462 & 108 & \multirow{2}{*}{$0.82(0.57-1.18)$} \\
\hline$\geq 11$ & 329 & 36.6 & 276 & 53 & \\
\hline \multicolumn{6}{|l|}{ Sex } \\
\hline Male & 499 & 55.5 & 413 & 86 & \multirow{2}{*}{$1.11(0.79-1.56)$} \\
\hline Female & 400 & 44.5 & 325 & 75 & \\
\hline \multicolumn{6}{|l|}{ Nationality } \\
\hline Saudi & 829 & 92.2 & 679 & 150 & \multirow{2}{*}{$0.84(0.43-1.65)$} \\
\hline Non-Saudi & 70 & 7.8 & 59 & 11 & \\
\hline \multicolumn{6}{|l|}{ Education } \\
\hline None & 327 & 36.4 & 246 & 81 & \multirow{2}{*}{$0.49(0.35-0.70)$} \\
\hline Literate & 572 & 63.6 & 492 & 80 & \\
\hline \multicolumn{6}{|l|}{ Residence } \\
\hline Urban & 870 & 96.8 & 717 & 153 & \multirow{2}{*}{$1.79(0.78-4.11)$} \\
\hline Rural & 29 & 3.2 & 21 & 8 & \\
\hline \multicolumn{6}{|c|}{ Parental consanguinity } \\
\hline Yes & 448 & 49.8 & 355 & 93 & \multirow{2}{*}{$0.69(0.48-0.96)$} \\
\hline No & 451 & 50.2 & 383 & 68 & \\
\hline \multicolumn{6}{|c|}{ Perinatal complications ${ }^{a}$} \\
\hline Yes & 376 & 45.8 & 280 & 96 & \multirow{2}{*}{$2.84(1.94-4.14)^{\mathrm{b}}$} \\
\hline No & 445 & 54.2 & 397 & 48 & \\
\hline Order among & & & & & \\
\hline$\leq 6$ & 689 & 83.1 & 571 & 118 & $126(080-199)$ \\
\hline$\geq 7$ & 140 & 16.9 & 111 & 29 & $1.20(0.00-1.99)$ \\
\hline No. of siblings & & & & & \\
\hline$\leq 9$ & 431 & 83.1 & 324 & 107 & $103(060-176)$ \\
\hline$\geq 10$ & 83 & 16.9 & 62 & 21 & $1.05(0.00-1.70)$ \\
\hline No. of visits to & & & & & \\
\hline$\leq 14$ & 818 & 91.0 & 665 & 153 & $0.48(0.23-1.01)$ \\
\hline$\geq 15$ & 81 & 9.0 & 73 & 8 & $0.40(0.23-1.01)$ \\
\hline Age of onset $\mathrm{o}$ & & & & & \\
\hline$\leq 5$ & 852 & 94.8 & 699 & 153 & $0.94(0.43-2.05)$ \\
\hline$\geq 6$ & 47 & 5.2 & 39 & 8 & $0.94(0.43-2.05)$ \\
\hline Symptoms $^{a}$ & & & & & \\
\hline$\leq 5$ & 230 & 25.6 & 209 & 21 & $264(159-4.43)^{b}$ \\
\hline$\geq 6$ & 667 & 74.4 & 527 & 140 & $2.04(1.59-4.43)^{\circ}$ \\
\hline Stressful life e & & & & & \\
\hline Yes & 460 & 51.2 & 363 & 97 & $064(045-090)$ \\
\hline No & 439 & 48.8 & 375 & 64 & $0.04(0.45-0.30)$ \\
\hline Family history & & & & & \\
\hline Yes & 283 & 31.5 & 219 & 64 & 064 (0 45-0 91) \\
\hline No & 616 & 68.5 & 519 & 97 & $0.04(0.45-0.91)$ \\
\hline Psychiatric co & & & & & \\
\hline Yes & 364 & 40.5 & 235 & 129 & $0.12(0.08-0.18)$ \\
\hline No & 534 & 59.5 & 502 & 32 & \\
\hline Psychiatric co & & & & & \\
\hline$\geq 3$ & 104 & 11.6 & 14 & 90 & $002(0,01-003)$ \\
\hline$\leq 2$ & 795 & 88.4 & 724 & 71 & $0.02(0.01-0.03)$ \\
\hline Physical como & & & & & \\
\hline Yes & 269 & 29.9 & 171 & 98 & $019(013-0$ \\
\hline No & 630 & 70.1 & 567 & 63 & $0.13(0.10-0.20)$ \\
\hline
\end{tabular}

${ }^{a}$ Data missing for some cases. ${ }^{b} P<0.05$.

$O R=$ odds ratio; $C l=$ confidence interval. 


\begin{tabular}{lcc}
\hline \multicolumn{3}{l}{ Table 2 Psychopathological symptoms recorded in records of children and } \\
adolescents attending child psychiatric clinics $(\boldsymbol{n}=\mathbf{8 9 9})$ \\
Symptoms $^{\mathrm{a}}$ & No. & $\%$ \\
Hyperactivity & 386 & 42.9 \\
Poor scholastic performance & 296 & 32.9 \\
Delayed milestones & 255 & 28.4 \\
Anxiety and related manifestations & 157 & 17.5 \\
Attention and concentration difficulties & 121 & 13.5 \\
Impulsivity & 120 & 13.3 \\
Speech and language difficulties & 109 & 12.1 \\
Seizures (tonic/clonic convulsions) & 92 & 10.2 \\
Incontinence of urine/stool & 87 & 9.7 \\
Poor eye contact & 69 & 7.7 \\
Stereotype behaviour including movements & 57 & 6.3 \\
Low mood & 49 & 5.5 \\
School refusal & 45 & 5.0 \\
Social isolation & 40 & 4.5 \\
Other behavioural and vegetative dysfunction &
\end{tabular}

aMore than 1 symptom could be recorded.

${ }^{b}$ Including easy provocation and aggression, hallucinatory behaviour, stealing, demanding and manipulative behaviour, sexual behaviour, disobedience, stubbornness, crying spells, sleep and appetite problems, poor hygiene.

derivatives, mood stabilizers, antiepileptic medications, benzodiazepines and hypnotics. Only 1 drug was prescribed in $64.9 \%$ of cases.

Psychotherapy was prescribed at the index evaluation for $55.2 \%$ of patients and at the last follow-up evaluation for $54.7 \%$ (more or less the same treatment). The therapeutic modalities included a wide variety of strategies, such as counselling, reassurance, behaviour

therapy, family therapy, psychoeducation, social support, speech therapy, play therapy, rehabilitation programmes (e.g. training in activities of daily life, social skills development, cleaning, dressing, etc.) and cognitive-behaviour therapy.

\section{Outcome}

Outgoing referrals were noted in $27.2 \%$ of patients' records for a variety of documented reasons, mainly medical

\begin{tabular}{lcc}
\hline $\begin{array}{l}\text { Table } 3 \text { Principal diagnosis recorded for children and adolescents attending child } \\
\text { psychiatric clinics }(\boldsymbol{n}=\mathbf{8 9 9})\end{array}$ & No. & $\%$ \\
\hline Principal diagnosis & 271 & 30.2 \\
Mental retardation & 145 & 16.1 \\
Anxiety disorder & 119 & 13.2 \\
Attention-deficit hyperactivity disorder & 112 & 12.5 \\
Autistic spectrum disorder & 87 & 9.7 \\
Seizure disorder & 38 & 4.2 \\
Mood disorder & 38 & 4.2 \\
School refusal & 28 & 3.1 \\
Enuresis and encopresis & 26 & 2.9 \\
Psychosis (organic and non-organic) & 35 & 3.9 \\
Other disorder &
\end{tabular}

ancluding tic disorder, stuttering, selective mutism, adjustment disorder, $V$-code diagnoses, avoidant personality traits, conduct disorder, oppositional defiant disorder, sexual abuse or conversion disorder. problems such as acute infections with fever, self-inflicted injuries, druginduced acute medical conditions (e.g. low blood pressure, dystonia etc.) Outcome was classified in the patients' files as good or bad, stable or unstable, moderate improvement or no improvement, and controlled versus uncontrolled. A stable outcome at the last follow-up consultation was reported in 738 $(82.1 \%)$ of medical files and unstable outcome in 161 (17.9\%).

Table 4 shows the linear regression analysis of outcome (stable/unstable) according to various sociodemographic and clinical variables. There was no significant association of outcome with age, sex, nationality (Saudi/non-Saudi), educational level or residence (urban/ rural). Family variables such as parental consanguinity, birth order, number of siblings and family history of psychiatric illness, were also not significant. Comorbidities (psychiatric or physical) also had not association. Only maternal perinatal complications and polypsychopathological symptoms had a significant association with outcome. Patients with complications were nearly 3 times more likely to have an unstable course than their counterparts without perinatal complications (OR 2.84, 95\% CI: 1.94-4.14). Patients with a high number of any symptoms ( $\geq 6$ symptoms) were more than twice as likely to have a poor outcome compared with patients having fewer symptoms (OR 2.64, 95\% CI: 1.59-4.43).

\section{Discussion}

This hospital-based study has given a broad view of the complex nature of mental health problems, service utilization and outcome measures in child and adolescent psychiatric clinics in Saudi Arabia. This study revealed the general sociodemographic profile of the children diagnosed with psychiatric disorders in the selected clinics. There was a nearly equal distribution of the 


\begin{tabular}{|c|c|c|}
\hline Treatment prescribed & No. & $\%$ \\
\hline \multicolumn{3}{|c|}{ Psychotropic drugs ${ }^{a}$ (at index evaluation) } \\
\hline 1 drug & 583 & 64.9 \\
\hline 2 drugs & 158 & 17.6 \\
\hline 3 drugs & 34 & 3.8 \\
\hline \multicolumn{3}{|c|}{ Psychotropic drugs ${ }^{a}$ (at current/last evaluation) } \\
\hline 1 drug $^{b}$ & 584 & 65.0 \\
\hline 2 drugs $^{c}$ & 272 & 30.3 \\
\hline 3 drugs $^{\text {d }}$ & 112 & 12.5 \\
\hline 4 drugs $^{e}$ & 23 & 2.6 \\
\hline \multicolumn{3}{|c|}{ Psychotherapy f (at index evaluation) } \\
\hline Yes & 496 & 55.2 \\
\hline \multicolumn{3}{|c|}{ Psychotherapyf (at current/last evaluation) } \\
\hline Yes & 492 & 54.7 \\
\hline
\end{tabular}

ancluding antipsychotic, anticholinergic, antidepressant plus selective serotonin reuptake inhibitor, psychostimulant derivative, mood stabilizer, antiepileptic, benzodiazepine or hypnotic types.

${ }^{b}$ As above.

Including carbamazepine, valproic acid, risperidone, imipramine or anticholinergic type. "Including benzodiazepine, valproic acid or anticholinergic type.

eIncluding anticholinergic type.

fIncluding counselling, reassurance, behaviour therapy, family therapy, psychoeducation, social support, speech therapy, play therapy, rehabilitation programme, and cognitive-behaviour therapy.

sexes, albeit with a slight preponderance of males, a low level of education in two-thirds of patients, and a majority living in urban areas. Another survey of inpatient child and adolescent psychiatric referrals in a teaching hospital in Saudi Arabia revealed that most of them were less than 12 years and females outnumbered males [17] and in an epidemiological study of secondaryschool children (aged 18-20 years) depression was more common among girls compared with boys [19].

The sources of incoming referral, almost all from public health settings (92.8\%), and the types of outgoing referrals (internal and external consultations) and purposes of referrals, especially diagnostic and management, were consistent with other studies in this country [17-19].

According to this study a variety of psychopathological symptoms were recorded which clustered into: inattention, hyperactivity and impulsivity; delayed milestones, poor scholastic skills, delayed speech and incontinence; anxiety- and low mood; poor eye contact, social isolation and communication/ speech difficulties; seizures; school refusal; and stereotyped behaviour. The most frequently noted principal diagnoses were mental retardation, $\mathrm{ADHD}$, anxiety disorder, autistic spectrum disorder, seizures, depressive disorder, school refusal, enuresis/encopresis and psychosis; this diagnostic trend is more or less consistent with other hospital studies in Saudi Arabia [17-19]. In a community survey of 4-year-olds in the United States, similar symptom and diagnostic patterns-ADHD, anxiety disorders, depressive disorders and oppositional defiant disorder - were found [11].

The prevalence of psychiatric (40.5\%) and physical (29.9\%) comorbidities among the studied patients was considerably higher than that reported in an epidemiological survey of a child and adolescent population elsewhere (overall co-morbidity rate of 6.4\%) [11], which would be expected in a community survey. But these higher prevalence figures agree with the rate of comorbid disorders reported in a study of adults referred patients to psychiatric hospitals in Saudi Arabia (38\% physical comorbidity rate) [20]. Evidently adult psychopathology may mirror the pattern of childhood psychopathology. The importance of this observation is that children and adolescents need comprehensive assessment in order not only to make the principal diagnosis but also to determine other comorbid psychiatric and physical disorders and their possible underlying causative factors. Treatment plans should address all recognized risk factors and disorders at their earliest stages in order to improve the overall outcome of patients.

The prescribing pattern of medications and non-drug interventions and utilization of other services is consistent with the relevant literature $[17,21]$. In studies of adults attending psychiatric treatment services in Saudi Arabia similar patterns of prescribing, which corresponded with the diagnostic categories, were reported $[22,23]$. The rate of polypharmacy, however, was higher in adult patients with mental disorders (85\%) in another study [23] compared with that for children and adolescents in the present study $(21.4 \%$ at the index evaluation). Prescribing of psychotherapy (alone or in combination with drug treatment), especially counselling, supportive therapy, family therapy, play therapy behavioural modification and psychoeducation, to children and adolescents with mental health problems is standard practice [24]. From our research it was difficult to comment on whether the prescribing of psychotropic drugs and psychotherapies was rational and unassociated with adverse effects. However, the finding that a stable outcome was recorded for more than $80 \%$ of studied patients is a reflection of the likelihood that the drug and non-drug interventions prescribed were appropriate.

There is considerable evidence about biological and psychosocial risk factors that may have an etiological role in mental disorders not only in children 
but also in adults. These include parental consanguinity, family history of mental disorders, large number of siblings, order of the child among siblings, parental marital problems, maternal multiparity, maternal perinatal problems, dysfunctional families, multiple marriages and parental relationship problems, financial difficulties, domestic violence and child abuse [14,25-28]. Although in the current study psychiatric and physical comorbidities were noted in a high proportion of cases (as mentioned above) and a family history of similar or dissimilar psychiatric disorder was reported in nearly one-third of children, among the factors studied only perinatal complications and number of symptoms were significantly associated with unstable outcome. It is recommended that perinatal services need to be improved further to reduce future complications including development of comorbid conditions
There were some limitations of the current study including the retrospective study design. However, it should be noted that there was no selection bias as all files recorded in the computer list were audited. Other strengths of the study included the selection of child psychiatric clinics with good data documentation by psychiatrists, multiple sources of recorded data and recent data notation. Nevertheless we suggest that the findings should be interpreted cautiously and it should be noted that data from a hospital-based study are not generalizable to the general child and adolescent population. Therefore a cross-sectional study using structured diagnostic schedule should be conducted to assess the child and adolescent mental health services in Saudi Arabia more comprehensively. Future research should also focus on the prevalence of specific childhood and adolescent mental disorders in the community nationwide.
In summary, this retrospective study provided a broad idea of pattern of sociodemographic profile, risk factors (especially perinatal complications and multiple symptoms), psychopathological symptoms and diagnoses, comorbid conditions, drug and non-drug prescribing and service utilization by child and adolescent patients consulting child psychiatric clinics in Saudi Arabia.

\section{Acknowledgements}

The investigators sincerely acknowledge the financial support provided by the UNICEF for conducting this study. We also express our thanks for the Scientific Committee of the General Administration for Medical Research, Ministry of Health for giving us the permission to carry out this research.

\section{References}

1. Murray CIL, Lopez AD, eds. The global burden of disease. Cambridge Massachusetts, Harvard University Press on behalf of the World Health Organization and World Bank, 1996:201-246.

2. McKelvey RS et al. The prevalence of psychiatric disorders among Vietnamese children and adolescents. Medical Journal of Australia, 2002, 17:410-413.

3. Eapen $\mathrm{V}$ et al. Childhood behavioral disturbance in a community sample in Al-Ain, United Arab Emirates. Eastern Mediterranean Health Journal, 2001, 7:428-434

4. Atlas: Child and adolescents mental health resources. Global concerns: implications for the future. Geneva, World Health Organization, 2005.

5. Kelley SD, Van Horn M, Demaso DR. Using process evaluation to describe a hospital-based clinic for children coping medical stressors. Journal of Pediatric Psychology, 2001, 26:407-415.

6. Ringeisen H, Oliver KA, Menvielle E. Recognition and treatment of mental disorders in children: considerations for pediatric health systems. Paediatric Drugs, 2002, 4:697-703.

7. Elgen I, Sommerfelt K, Markestad T. Population based, controlled study of behavioral problems and psychiatric disorders in low birthweight children at 11 years of age. Archives of Disease in Childhood. Fetal and Neonatal Edition, 2002, 87:128-132.

8. Zima B et al. Quality of publicly-funded outpatient specialty mental health care for common childhood psychiatric disorders in California. Journal of the American Academy of Child and Adolescent Psychiatry, 2005, 44:130-144.
9. Staller JA. Diagnostic profiles in outpatient child psychiatry. American Journal of Orthopsychiatry, 2006, 76:98-102.

10. Golubchik P et al. Neurosteroids in child and adolescent psychopathology. European Journal of Neuropsychopharmacology, 2007, 17:157-164.

11. Lavigne JV et al. The prevalence of ADHD, ODD, depression, and anxiety in a community sample of 4-year-olds. Journal of Clinical Child and Adolescent Psychology, 2009, 38:315-328.

12. Domenech-Llaberia E et al. Prevalence of major depression in preschool children. European Child and Adolescent Psychiatry, 2009, 18(10):597-604.

13. Lus G, Mukaddes NM. Comorbidity of bipolar disorder in children and adolescents with attention-deficit-hyperactivity disorder in an outpatient Turkish sample. World Journal of Biological Psychiatry, 2009, 10:1-7.

14. Otero S. Psychopathology and psychological adjustment in children and adolescents with epilepsy. World Journal of Pediatrics, 2009, 5:12-17.

15. Hofvander B et al. psychiatric and psychosocial problems in adults with normal intelligence autism spectrum disorders. BMC Psychiatry, 2009, 9:35-42.

16. Reef J et al. Child to adult continuities of psychopathology: a 24-year follow-up. Acta Psychiatrica Scandinavica, 2009, 120(3):230-238.

17. Al-Haidar FA. Survey of inpatients child and adolescent psychiatric referrals in a teaching hospital in Saudi Arabia. Neurosciences, 2003, 8:43-45.

18. Qureshi NA et al. Psychiatric referrals. In primary care and general hospitals in Qassim Region, Saudi Arabia. Saudi Medical Journal, 2001, 22:619-624. 
19. Asal AR, Abdel-Fattah MM. Prevalence, symptomatology, and risk factors for depression among high school students in Saudi Arabia. Neurosciences, (Riyadh), 2007, 12(1):8-16.

20. Qureshi NA, Al-Habeeb TA, Al-Ghamdy YS. Magzoub MMA, Schmidt HG, van der Molen HT. Psychiatric comorbidity in primary care and general hospitals, Saudi Arabia. Eastern Mediterranean Health Journal, 2001, 7:492-501.

21. Lyons JS et al. Psychotropic medications prescribing patterns for children and adolescents in New York's public mental health system. Community Mental Health Journal, 2004, 40:101-118.

22. Qureshi NA et al. Psychotropic drug prescriptions in primary care and general hospitals in Saudi Arabia. Saudi Pharmaceutical Journal, 2001, 9:193-200.

23. Al-Ghamdy YS et al. A study of psychotropic drugs prescriptions in Al-Qassim region, KSA. Eastern Mediterranean Health Journal, 1999, 5:27-34.

24. Compton SN, March JS, Brent D. Cognitive-behavioral psychotherapy for anxiety and depressive disorders in children and adolescents: an evidence-based medicine review. Journal of the American Academy of Child and Adolescent Psychiatry, 2004, 43:930-959.

25. Mental health: a report of the Surgeon General. Washington DC, US Department of Human and Health Services, 1999.

26. Maternal mental health and child health and development in low and middle income countries. Geneva, World Health Organization and United Nations Population Fund, 2008.

27. Hicks BM et al. Environmental adversity and increasing genetic risk for externalizing disorders. Archives of General Psychiatry, 2009, 66:640-648.

28. Huang Y, Collier D, Li T. A prospective twin registry in Southwestern China (TRiSC): exploring the effects of genetic and environmental factors on cognitive and behavioral development and mental health wellbeing in children and adolescents. Twin Research and Human Genetics, 2009, 12:312-319.

\section{Maternal, child and adolescent mental health: challenges and strategic directions for the Eastern Mediterranean Region}

Maternal, child and adolescent mental disorders constitute a public health problem. The estimated prevalence of 15\%-36\% for maternal mental disorders and 10\%-36\% for child and adolescent mental disorders in the WHO Eastern Mediterranean Region is significantly higher than the estimates for developed countries. Mental disorders among mothers, children and adolescents are inextricably linked, at the causal as well as at the intervention level, making it imperative to address the issue in an integrated manner. Maternal, child and adolescent mental health: challenges and strategic directions for the Eastern Mediterranean Region provides an overview of the situation globally and regionally, identifies the major challenges and suggests strategic directions and actions to promote maternal, child and adolescent mental health in the Region. The strategic directions outlined were endorsed by the WHO Regional Committee for the Eastern Mediterranean in 2010. The publication is aimed at policy-makers, health system managers, mental health professionals and others interested in mental health in general, and maternal, child and adolescent mental health issues in particular. It will help countries in developing national strategies and action plans based on evidence and in charting progress in provision of integrated mental health services for maternal, child and adolescents. In turn, this will help in achievement of the Millennium Development Goals.

This full text of this publication can be accessed online at: http://www.emro.who.int/dsaf/dsa1214.pdf 